\title{
ANALYSIS OF THE WORMWHEEL TOOTHING ACCURACY
}

\author{
Tadeusz, Nieszporek, Rafal Gołębski, Lubomir Šooš
}

Original scientific paper

The article presents a mathematical model for the determination of the tooth surface of the wormwheel machined by either the tangential or the radial method. Wormwheel machining with a special hob and a modular hob is considered. Different methods of solving the task are presented. This includes also a numerical method that requires the envelope condition to be solved. The described discussion is general in nature. The tool action surface, built based on the worm mating with the wormwheel in the worm gear, may have an arbitrary profile. In the technological gear, made up by the tool and the wormwheel, the rotary motion of the wormwheel was exchanged for its rectilinear motion. The tool positioning errors in the machining process were taken into account.

Keywords: envelope method; worm gear; wormwheel

\section{Analiza točnosti ozubljenja pužnog kola}

Izvorni znanstveni članak U radu se predstavlja matematički model za određivanje površine zubi pužnog kola obrađenog bilo tangencijalnom bilo radijalnom metodom. Razmotrena je obrada pužnog kola specijalnim pužnim glodalom i modularnim pužnim glodalom. Predstavljene su različite metode rješavanja zadatka uključujući i numeričku metodu koja zahtijeva rješenje stanja ovojnice. Opisana rasprava je općenite prirode. Radna površina alata, izrađena na osnovu puža spojenog s pužnim kolom u pužni zupčanik, može biti proizvoljnog profila. U tehnološkom zupčaniku, sastavljenog od alata i pužnog kola, rotacijsko gibanje pužnog kola je zamijenjeno pravocrtnim gibanjem. U obzir su uzete greške pozicioniranja alata u postupku obrade.

Ključne riječi: metoda ovojnice; pužno kolo; pužni zupčanik

\section{Introduction}

Worm gears find wide application [1, 2], chiefly in reduction gears and gear-motors [3]. In heavy industry (such as metallurgy or mining), large-size worm gears designed for carrying large loads are often used, whose manufacturing costs are very high and whose accuracy, durability and reliability should meet appropriate operational conditions. The surface of the wormwheel toothing is machined by either tangential or radial method in the hobbing process $[4,5,6]$, the tool (its action surface) and the wormwheel being machined from the technological worm gear in the machining process [7]. The inaccuracy of tools, the machining errors and the assembly errors will cause accelerated intensive wear of the gear wormwheel toothing - Fig. $1[8,9,10]$.

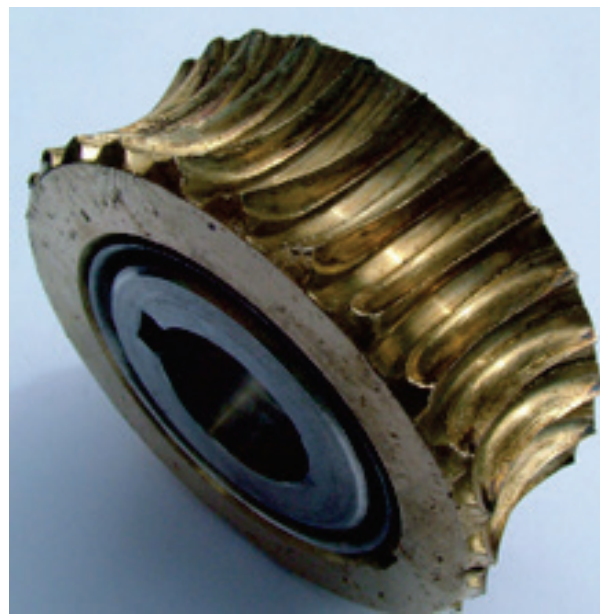

Figure 1 An example of wormwheel wear

The action surface of the wormwheel machining tool needs to be determined based on the surface of the design worm, which will form a worm gear with the wormwheel being machined [7, 11]. So, cutting wormwheels requires the use of special hobs [6] and, generally, is carried out on special machine tools [12]. In the case of unit production of large-module gears, this is difficult to accomplish due to the costs of special wormwheel cutting hobs, which in practice are often substituted with modular hobs [13]. The literature has given much coverage to the formation of the helical surfaces of worms [4,14], while there are few studies concerning the generation of wormwheel toothing, especially using modular hobs, or the tooth contact analysis (TCA) [15, 16, 17], especially by numerical methods [18, 19]. TCA is the primary criterion for assessing the quality of a worm gear drive [20, 21]. Therefore, this paper has presented a universal numerical method of generating wormwheel toothing by the envelope method for determining the wormwheel machining accuracy.

\section{The technological gear}

The basis for the classification of worm gears is generally the worm helical surface (machining by turning) [22] or the axial profile of the wormwheel machining tool action surface (machining by milling and grinding) [23]. In practice, cone-derivative helical surfaces [24, 25] shaped with a disc-, finger-, cup- or ring-type rotary tool are predominating. This is envelope machining $[4,26]$, and the axial profile of the tool action surface is rectilinear $[4,5]$, though, in a general case, it can be arbitrary. If we consider the relative tool and worm helical motion, then the family of tool action surfaces in the worm's coordinate system can be notated with the following equation:

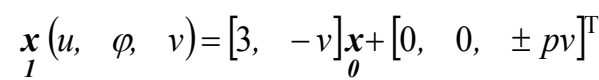


where: $u$ - tool profile parameter; $\varphi$ - rotary tool action surface parameter; $v$ - relative helical motion parameter (tool action surface family parameter); $\underset{\boldsymbol{0}}{\boldsymbol{x}}$ - vector of tool positioning in the worm's system.

Whereas, the helical surface parameter is

$$
p=\frac{h}{2 \pi}
$$

where: $h$-worm helical surface pitch.

In order to describe the worm surface, the envelope condition [5, 24] needs to be added to Eq. (1).

$$
f_{1}=\frac{\partial \boldsymbol{x}}{\partial u} \frac{\partial \boldsymbol{x}}{\partial \varphi} \frac{\partial \boldsymbol{x}}{\partial v}=0
$$

So, the worm convolution surface will be described by the system of equations (while keeping in mind that the characteristic feature of the envelope condition is in this case the fact that it does not include the parameter of relative tool and worm helical motion).

$$
\begin{aligned}
& \underset{1}{\boldsymbol{x}}=\underset{1}{\boldsymbol{x}}(u, \quad \varphi, \quad v) \\
& f_{1}(u, \varphi)=0
\end{aligned}
$$

The worm surface is a starting surface for determining the action surface of the special wormwheel toothing machining hob. The worm surface can be known beforehand, for example from measurements. In that case, the action surface of the tool (hob) is described by the following equation:

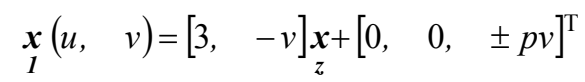

where: $u$-hob action surface axial profile parameter; $v-$ hob action surface (the axial profile helical motion parameter in the worm's coordinate system); $\underset{z}{\boldsymbol{x}}$-worm axial profile.

Similarly, the action surface of the modular wormwheel cutting hob can be either calculated or obtained from measurements. This means that the worm helical surface (tool action surface) for wormwheel toothing surface generation is described by the system of Eqs. (4) and (5) or Eq. (6). In the machining process, after the hob has been cut in to the full depth by the tangential or radial method, the tool (its action surface) and the wormwheel being machined will form a wormwormwheel technological gear - Fig. 2. If the action surface of the tool (hob) is identical to the surface of the worm that is to mate the wormwheel being machined, then the technological gear will correspond to the design worm gear. The worm-wormwheel gear, in which rotary motion around the axes of both gear elements occurs, can be substituted with an equivalent gear, where worm axiswise motion occurs with no rotation.

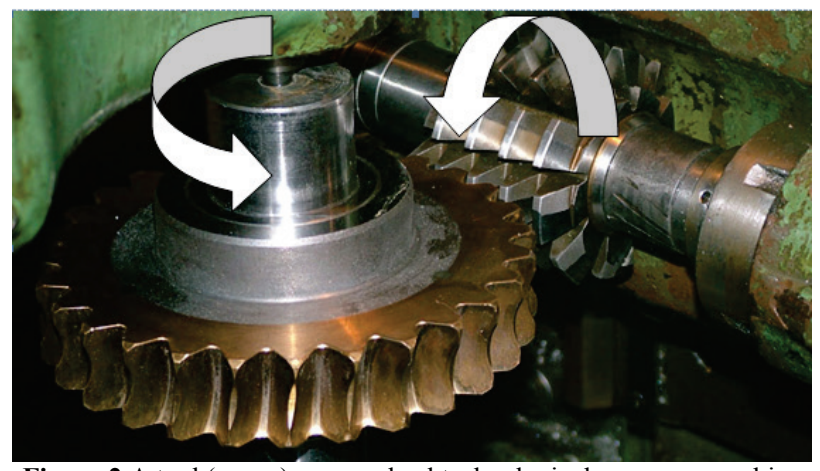

Figure 2 A tool (worm)-wormwheel technological gear on a machine tool

So, in order to determine the wormwheel toothing surface as the envelope of tool action surfaces, transition should be made from the worm (tool) system to the wormwheel system (Fig. 2), which can be notated with the equation below

$$
\begin{aligned}
& \underset{2}{\boldsymbol{x}}=\underset{\boldsymbol{2}}{\boldsymbol{x}}(u, \quad v, \quad \xi)=
\end{aligned}
$$

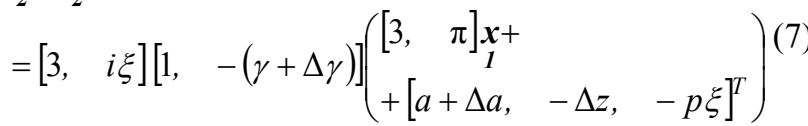

where: $\xi$ - relative tool and wormwheel turning motion parameter; $\gamma$ - angle between the tool and wormwheel rotation axes; $p$ - tool helical action surface parameter; $a$ - tool and wormwheel axis distance for machining by the tangential method; $\Delta a$ - axis distance error with the tangential method or the quantity allowing for the tool cutting into the machined wormwheel with machining by the radial method; $\Delta \gamma, \Delta z-$ tool positioning errors; $i-$ worm gear transmission ratio.

Whereas, the transmission ratio is equal to, respectively:

$i=\frac{z_{1}}{z_{2}}$

where: $z_{1}, z_{2}$ - number of worm and wormwheel teeth.

The tool action surface, corresponding to the worm surface, can be generally described by the system of Eqs. (4) and (5). If, from the envelope condition (5) (in which the relative helical motion parameter $\mathrm{V}$ occurs), the parameter $\varphi$ can be determined, then the equation of the worm surface (tool action surface) will assume a general form.

$\underset{1}{x}=\underset{1}{x}(u, \quad \varphi(u), v)=\underset{1}{x}(u, v)$

The family of tool action surfaces in the wormwheel's system is written with Eq. (7). In order to determine the wormwheel tooth surface, the envelope condition should be added to this equation. The general form of this envelope condition is, in the case under consideration, the following:

$$
f_{2}=\frac{\partial \underset{\boldsymbol{2}}{\boldsymbol{x}}}{\partial u} \frac{\partial \boldsymbol{2}}{\partial v} \frac{\partial \boldsymbol{2}}{\partial \xi}=0
$$


The first factor in this equation is calculated from Eq. (7), while considering Eq. (9). The next component of product (10) is determined from Eq. (7). The last component of condition (10) is determined from Eq. (6). Considering the fact that, in the triple product of three vectors, the common matrix of rotation acting upon each of the vectors can be omitted, then envelope condition (10) can be reduced, respectively, to the following form

$f_{2}=\boldsymbol{a} \boldsymbol{b} \boldsymbol{c}=0$

Where

$$
\begin{aligned}
& \boldsymbol{a}=\frac{\partial \boldsymbol{x}}{\partial u}+\frac{\partial \boldsymbol{x}}{\partial \varphi} \frac{\partial \varphi}{\partial u} \quad \boldsymbol{b}=\frac{\partial \boldsymbol{1}}{\partial v}
\end{aligned}
$$

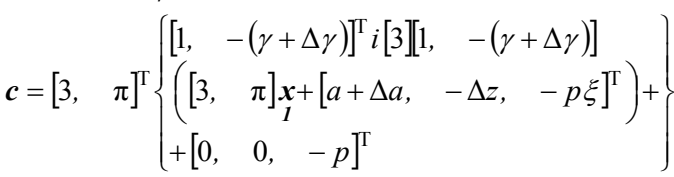

However, as Eqs. (12) imply, condition (10) is a linear function of the parameter $\xi$, which can therefore be determined from this equation in the form of an explicit function

$$
\xi=\frac{\boldsymbol{d}\left[[3, \quad \pi]^{\mathrm{T}} \boldsymbol{e}\right\}}{\boldsymbol{d}[3, \quad \pi]^{\mathrm{T}}\left[\begin{array}{ll}
1, & -(\gamma+\Delta \gamma)
\end{array}\right]^{\mathrm{T}} i[3]\left[\begin{array}{ll}
1, & -(\gamma+\Delta \gamma)
\end{array}\right]\left[\begin{array}{lll}
0, & 0, & p
\end{array}\right]^{T}}
$$

where the following designation is taken

$$
\begin{aligned}
& \boldsymbol{d}=\boldsymbol{a} \times \boldsymbol{b} \\
& \boldsymbol{e}=[1, \quad-(\gamma+\Delta \gamma)]^{\mathrm{T}} i[3][1, \quad-(\gamma+\Delta \gamma)] \\
& \left(\left[\begin{array}{cc}
3, & \Pi
\end{array}\right] \underset{1}{x}+\left[\begin{array}{lll}
a+\Delta a, & -\Delta z, & 0
\end{array}\right]^{\mathrm{T}}\right)+ \\
& +\left[\begin{array}{lll}
0, & 0, & -p
\end{array}\right]^{\mathrm{T}}
\end{aligned}
$$

The parameter $\Delta a$ defines the variable distance of the tool and wormwheel axes and, with the radial method, reflects the tool "cutting in" to the material being machined. In practice, this motion is continuous, but for the same wormwheel tooth, it assumes discrete values every single rotation.

So, for every single wormwheel rotation, that is for successive in-feed values, the wormwheel tooth surface needs to be determined and finally, by respectively juxtaposing (comparing) thus obtained surfaces with one another, the tooth surface formed by the radial method should be determined. In other words, if subsequent tool indentations are omitted and only the case of tool and machined wormwheel turning for the full indentation depth $(\Delta a=0)$ is considered, then the wormwheel tooth surface formed by the tangential method will be obtained. As a result, the described algorithm enables the determination of the tooth surface of the wormwheel machined by either the tangential or the radial method.

It is accepted to determine the wormwheel tooth profile in the frontal section from condition below:

$$
f_{3}=\underset{2}{x^{3}}-s=0
$$

where $\boldsymbol{x}_{2}^{3}$ is the third component of the vector (12), while the parameter $s$ defines the position of the cutting plane relative to the frontal symmetry plane (situated in the mid-width of the rim and perpendicular to the axis).

\section{Shaping the wormwheel with a special hob}

It is assumed that the tool action surface is consistent with the specified worm surface. So, this is the case of wormwheel machining with a special hob designed for wormwheel machining (or with a single cutter).

The computation algorithm is explained in Fig. 3.

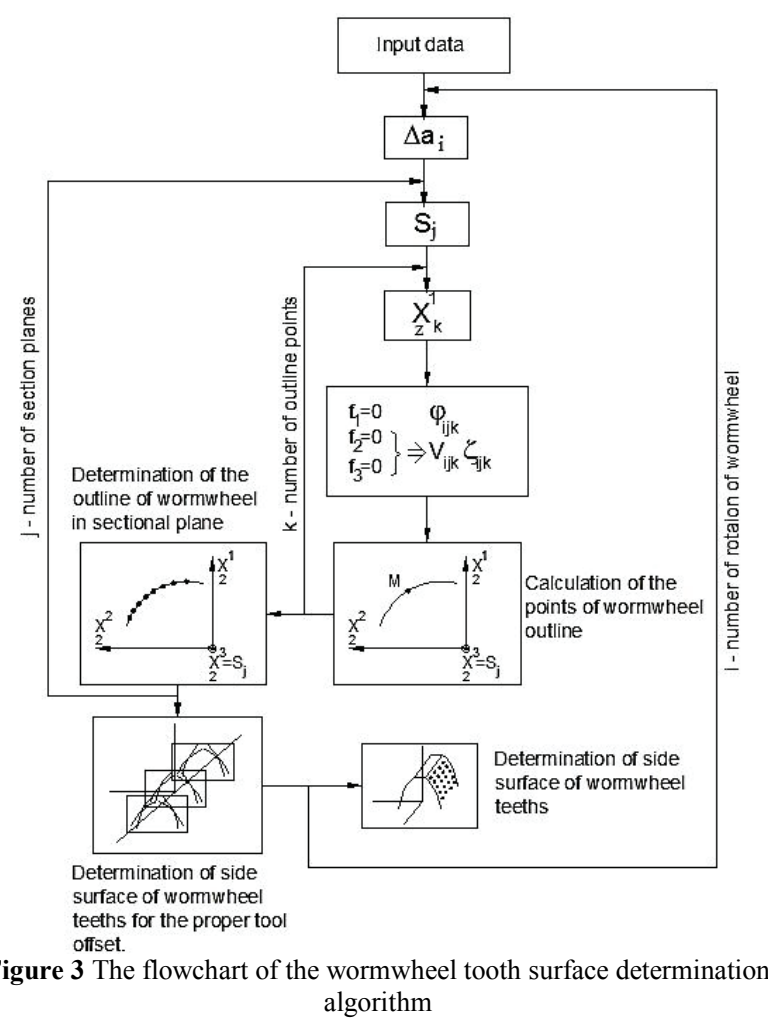

For a given value $\Delta a$ of tool offset (indentation) from the wormwheel in a given cutting plane defined by the parameter $s$, for successive values of a parameter, for example, $u$, the values of the parameters $\varphi$ are determined respectively from Eq. (5). From Eq. (16), the values of the parameter $v$ are determined by the successive approximations method, whereas, in each approximation, the value of the parameter $\xi$ is determined from Eq. (13). Ultimately, for each computation cycle, the values of the parameters $(u, \varphi, v, \xi)$ are determined, which, after being substituted in Eq. (7), will define the successive points of the wormwheel tooth profile.

Whereas, the value of cutting plane position changes and the computation cycle is repeated to yield, as a result, the wormwheel tooth surface in a discrete form of a set of points for a specific "indentation" of the tool into the wormwheel being machined.

After changing the $\Delta a$, the computation cycle is repeated for the same cutting planes. After that, the obtained profiles should be compared in these planes, while leaving the points on the work material side. After considering the successive tool in-feeds until reaching the 
full cutting depth $(\Delta a=0)$, and repeating the whole computation cycle, the wormwheel toothing surface is obtained.

The region of the worm and the wormwheel should be limited by their respective (outer and inner) diameters and the wormwheel rim width, and, with the radial method, the tool offset beyond the machined wormwheel region at the initial moment should be taken into account.

\section{Normalizing the profile points and the modification of the wormwheel toothing surface determination algorithm}

As follows from the above discussion, in individual cutting planes after successive tool passes (for varying cutting depths), the two curves given in a discrete form of sets of points should be each time compared with one another. Normalizing the points of the curve involves their approximation with the set of points lying on the abscissa grid lines introduced in the cutting plane (successive curves are substituted with the sets of points with the same abscissae, but different ordinates).

Finally, after considering the successive wormwheel rotations (tool "passes" and "indentations"), until achieving the full cutting depth $(\Delta a=0)$, the wormwheel tooth surface will be obtained in a discrete form of a set of points.

This method of determining the wormwheel tooth profile allows the simplification of the algorithm for the solution of the task set. So, if we take into account the cutting plane (16), then for a fixed value of the relative tool (worm) and wormwheel position parameter $\xi$, Eq. (7) will describe the worm profile in the wormwheel system (in this particular cutting plane). The helical surface can also be described with the helical motion of an arbitrary curve lying on this surface, so it is possible to take into consideration also the characteristics (the curve of worm machining tool and worm surface contact when shaping the worm helical surface).

With a fixed value of the relative worm machining tool and worm helical motion parameter $v$, Eq. (4) and (5) are the equations of the characteristics. As Eq. (5) does not include the parameter $v$, then, for successive values of a parameter, for example $u$, the values of the parameter $\varphi$ can be determined from this equation, and, in turn, from Eq. (4), the characteristics sought for. Thus, at a fixed value of the parameter $\xi$, for successive values of the parameter $u$, after determining the value of the parameter $\varphi$ from Eq. (5), it is possible to determine the values of the parameter $v$ from Eq. (16), and finally, the worm (hob) profile in a given cutting plane in the wormwheel system can be determined from Eq. (7). By iterating the whole computation process for successive values of the parameter $\xi$, successive curves can be obtained, which, after normalizing and comparing, enable us to determine the tooth flank profile in a given section for a given value of $\Delta a$. Further, the computation cycle is similar as before. In this method of solving the wormwheel tooth flank surface determination problem, there is no need for defining the envelope condition (10) (which is a significant simplification) and the computation algorithm is slightly different.

\section{Shaping the wormwheel with a modular hob}

In this case, the radial wormwheel machining method is employed. So, the relationship (7) describing the transition from the hob coordinate system to the wormwheel coordinate system still holds.

However, as the hob diameter usually does not correspond to the diameter of the worm (the module and the pitch must agree) which will mate the wormwheel being machined, the hob thread lead angle on the pitch diameter will be different from the worm thread lead angle [12]. So, the angle $\Delta \gamma$ will not be interpreted as an error, but rather as a necessary correction to the hob positioning (provided that the angle $\gamma$ corresponds, as before, to the angle of the axes of the hob-wormwheel design gear elements). The most important is, however, the fact that the hob blade cutting edge profiles are different from the worm profile (and the profiles of the left-hand and right-had hob blade cutting edges are different, too)

In the case of special hobs, the correct blade profile is obtained by leaving small bevels ("margins" of $0,03 \div$ $0,05 \mathrm{~mm}$ ) on the blades as a result of grinding the hob with the turning motion disabled (forming the helical hob action surface). It is assumed that the profiles of the hob cutting edges are known (from measurements or calculations). This enables us to determine the axial profile of the hob action surface, or, in general, the hob action surface, in the discrete form of a set of points.

It is assumed that the axial profile $\boldsymbol{x}$ (the coordinate system of the hob is adopted in a similar way as for the worm) of the modular hob action surface is given (just as other geometrical parameters needed for computation are). The modular hob action surface can therefore be described by the relationship:

$\underset{1}{\boldsymbol{x}}=[3, \quad-v] \boldsymbol{x}+\left[\begin{array}{lll}0, & 0, & \pm p v\end{array}\right]^{\mathrm{T}}$

where: $v$ - hob action surface parameter.

For the determination of the wormwheel tooth surface, the algorithm described above can be used after a slight modification.

\section{Computation results}

The wormwheel machining worm (the axial and normal profiles and, as a result, the surface) of the design type (tool action surface) is computed in the program, while allowing for the worm technology. The wormwheel profiles in successive sections - Fig. 4a make up the wormwheel tooth surface - Fig. $4 \mathrm{~b}$.

The program allows the elimination of a possible case of wormwheel tooth relief (in any section, the tooth tip width can be read out - Fig. 4a). In the case under consideration, it was sufficient to reduce the number of wormwheel teeth by 1 for wormwheel tooth relief to have occurred - Fig. 5 .

The reduction of the number of wormwheel teeth has a very strong effect on the tooth tip relief. At the same time it is possible to define how to change the geometrical wormwheel rim parameters so as to avoid the tooth tip relief, while retaining the existing number of teeth. 

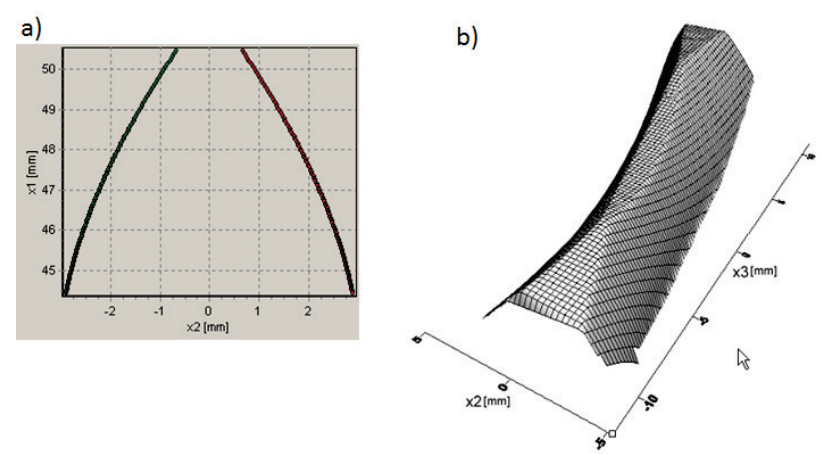

Figure 4 a) The wormwheel tooth profile in the cutting plane $s=0$ (values given - module, 3 ; multiplicity, 2 ; pitch diameter, 31 ; number of wormwheel teeth, 31; distance of the worm and wormwheel axes, 63); b) tooth view
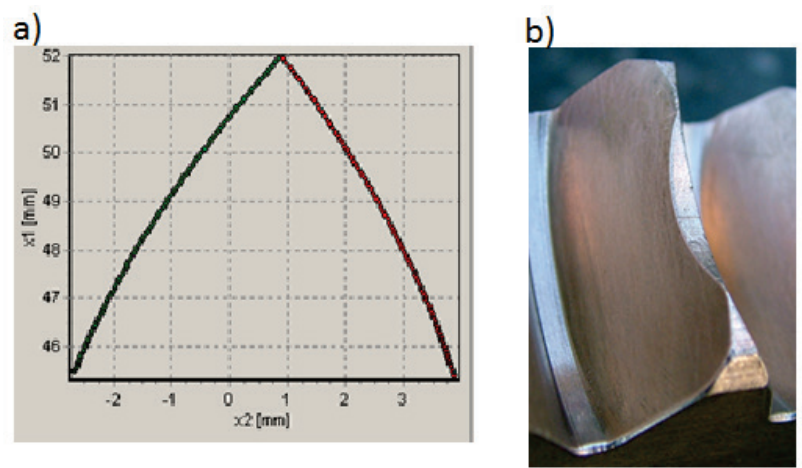

Figure 5 Wormwheel tooth tip relief: a) in the cross-section (cutting plane position $-S=7 \mathrm{~mm} ; z_{1}=1, z_{2}=30-$ other data as in Fig. 9); b) tooth view

Similarly, the correction of the profile by setting back the tool during wormwheel machining has also a strong effect on the tooth thickness and the tooth tip width - Fig. 6.

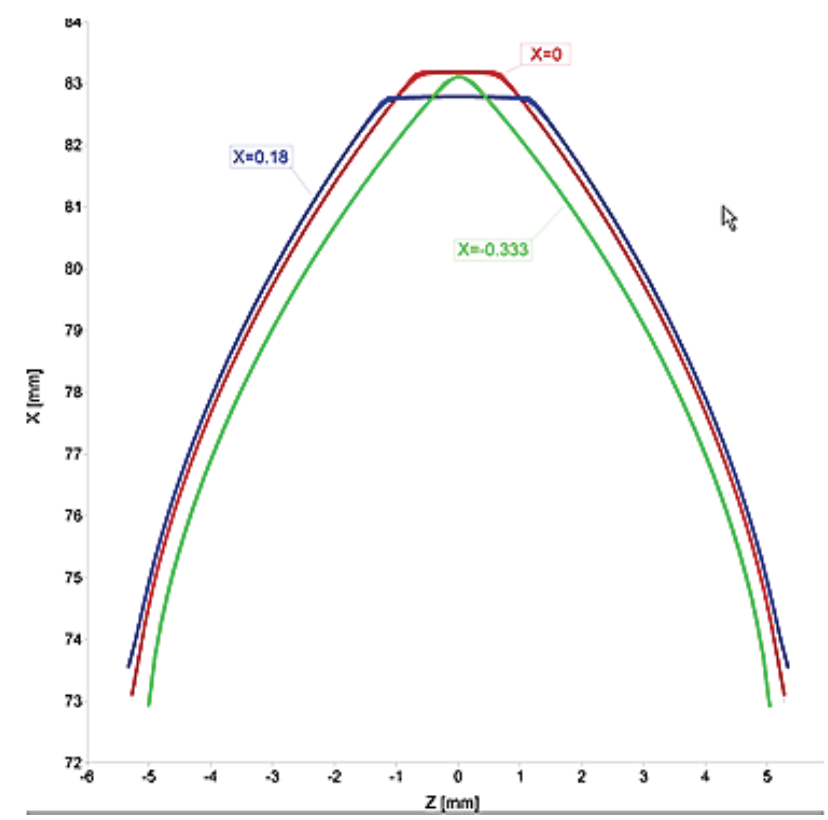

Figure 6 The effect of the tool offset on the tooth thickness ( $x-$ correction factor; the data as in Fig. 4)

If machining errors are taken into account, then the axis distance error results not only in a change in wormwheel tooth thickness, but also a change wormwheel profile - Fig. 7. It can be concluded, therefore, that the wear of the wormwheel machining tool (backed-off hob) compensated for by pushing it appropriately closer to the axis of the machined wormwheel, may result in a change of the wormwheel profile (the hob wear allowance of $(0,1$ $\div 0,05) m_{\mathrm{o}}$ should not be exceeded). In turn, the error of wormwheel axial positioning on the cutter arbor during machining is tantamount to moving the wormwheel rim toothing relative to the wormwheel axial plane - Fig. 8, which is tantamount to tooth tilting (and also the teeth will be lower). These errors, as can be seen in the example given, are relatively large and essentially impossible for being compensated for through the appropriate assembly of the gear.

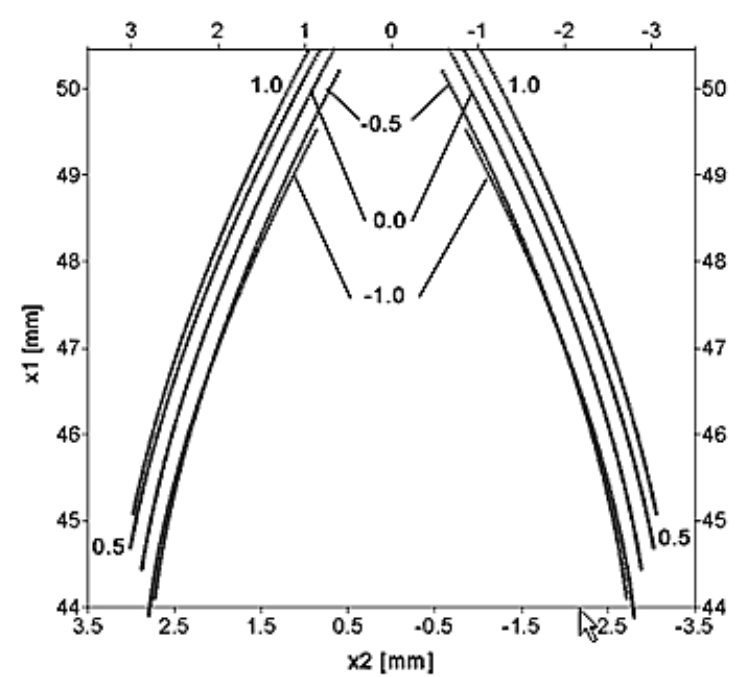

Figure 7 The effect of the technological worm and wormwheel axes distance error on the wormwheel profile in the frontal section at the midwidth of the rim (the data as in Fig. 9; indentation=var)

On the other hand, the angle error in the technological gear causes changes in tooth thickness of profile over the rim width (in the operational gear, it can lead to a wormwheel toothing truncation - Fig. 9. Therefore, the allowable errors between axes in the gear box are very small $\left(<0,5^{\circ}\right)$, and the permissible error angle of the technological gear should be of the same order of magnitude.

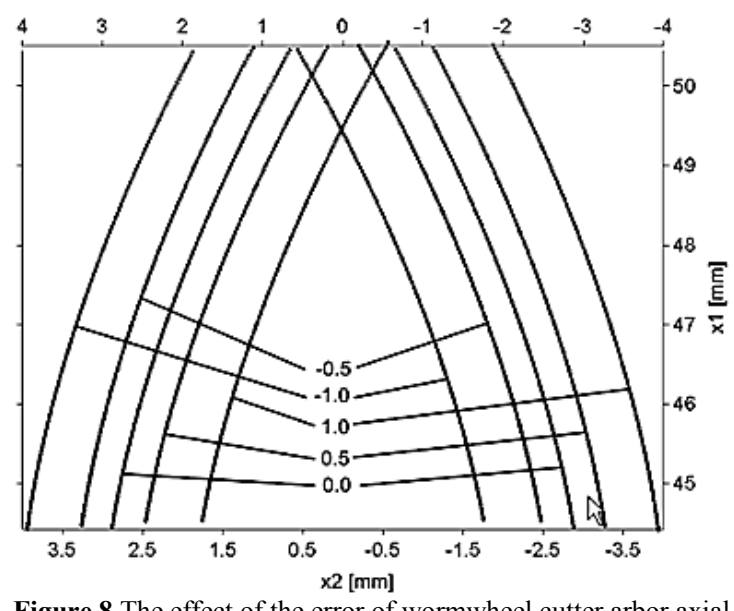

Figure 8 The effect of the error of wormwheel cutter arbor axial positioning on the wormwheel rim mid-width frontal section profile (the data as in Fig. 4; Deltaz=var)

It is also necessary to point out that if the change in the number of teeth significantly influences the tooth tip 
width, then setting the machine tool (indexing head) to too small a number of teeth will also lead to a truncation of the wormwheel toothing (in the case at hand, it is sufficient to take $z_{2}=24$ ).

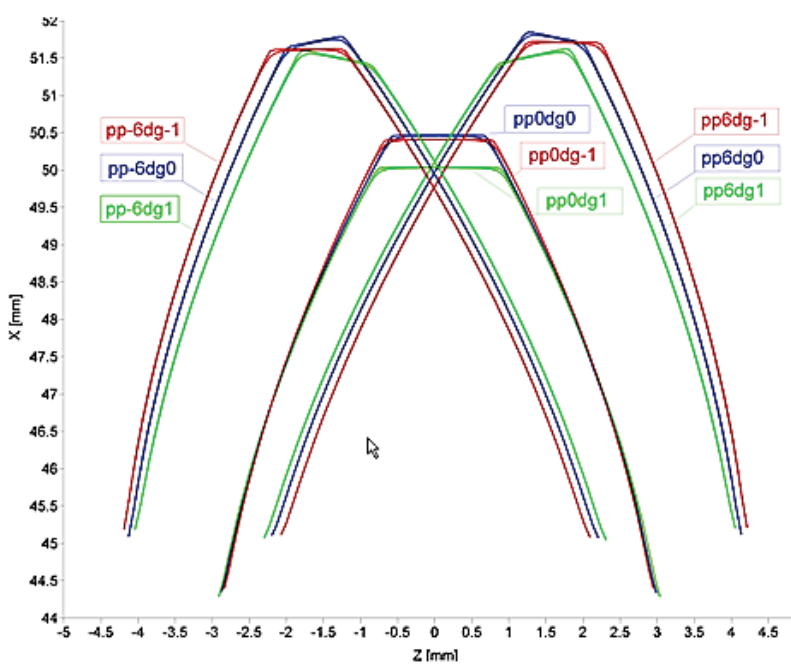

Figure 9 The effect of the error of tool and wormwheel milling machine positioning angle on the truncation of the wormwheel tooth flank (the data as in Fig. 4; The position of the cutting plane s (pp) $0 ; 6 ;-6 \mathrm{~mm}$; angle $\left.\Delta \gamma(\mathrm{dg})=0 ; 1 ;-1^{\circ}\right)$

The analytical and numerical method of generating the wormwheel toothing surface, in contrast to the analytical method, enables the determination of the undercutting or the transition curve (delineated by the tool blade tip) of the tooth profile - Fig. 10. This is due to the fact that in the case of undercutting at the points on the turn edge (the edge of the flank and transition surface intersection) the normal to the surface is not defined unequivocally and the meshing condition has no solution. In the analytical method, the envelope condition may have no solution (this is also the case with the bad first approximation of the root), while in the numerical method, a larger number of profile points needs generally to be considered and the computation time elongates.

According to the algorithms (programs) described above, wormwheel toothing can be formed by either tangential or radial method. The radial method enables the illustration of tooth formation as the tool cuts into the wormwheel being machined - Fig. 11 .

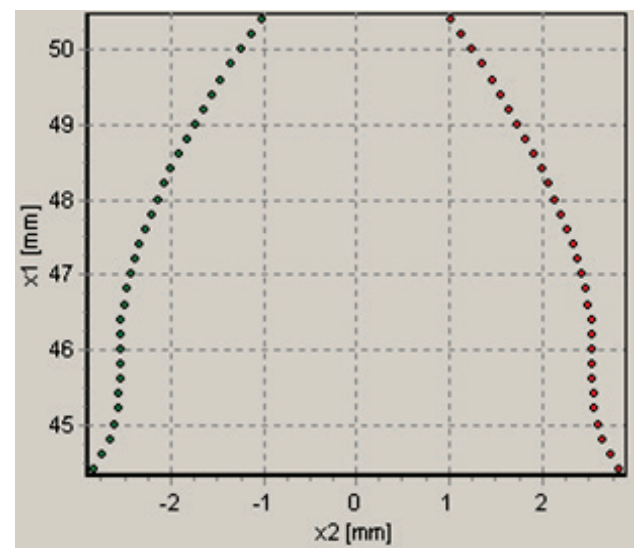

Figure 10 The wormwheel tooth profile in the cross-section at the rim mid-width (the data - Fig. 9)
This might enable, by comparing profiles of a specific cross-section (on the outer diameter on frontal surfaces) at the beginning and end of the indentation process, the elimination of the tooth tip truncation phenomenon (this phenomenon is rather unlikely in practice).

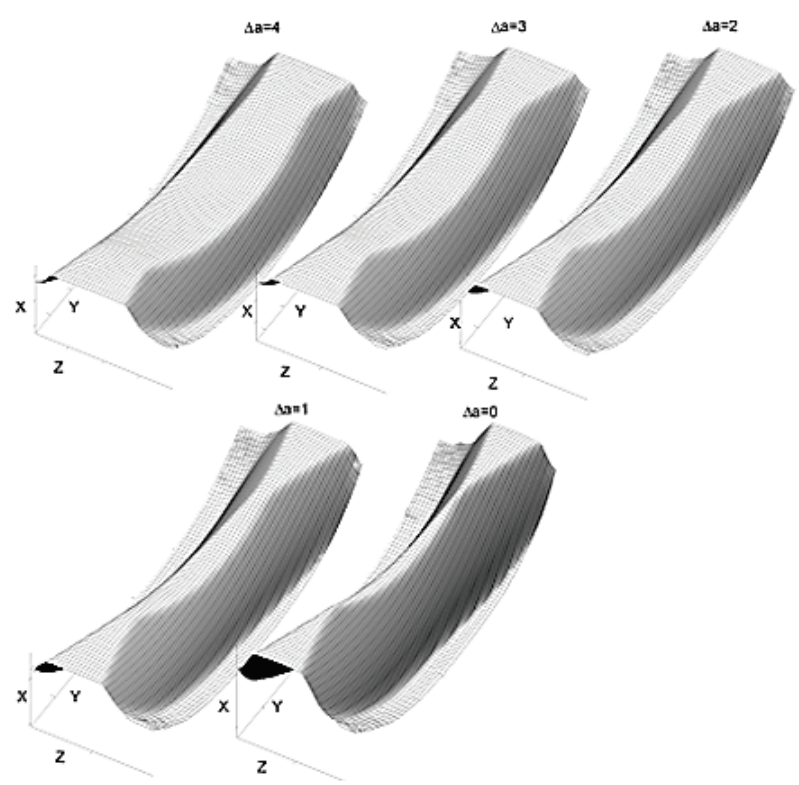

Figure 11 Illustration of the radial wormwheel toothing cutting method (the data - Fig. 9) - the parameter $\Delta$ a defines the indentation

As regards the wormwheel machining with a modular hob, on the other hand, it is assumed that the profile of the tool action surface is known. It can be obtained either from calculations or from measurements

The axial profile of the modular hob action surface is stored in a file (the program provides for a greater number of profile points and offers the capability to record necessary data). The left-hand and right-hand axial profiles of the modular hob action surface are different, and the profile angles are also different, which is unique to the tools under consideration. The straight line deviations of these profiles are different and should be contained within specific limits, depending on the hob accuracy class.

It is important to note that, in practice, the diameter of the modular hob is generally different from the diameter of the hob that will mate the wormwheel being cut. As a consequence, at the same axial pitch, the modular hob and worm thread lead angles are different, which needs to be taken into account in the modular hob-wormwheel technological gear. The wormwheel tooth surface profile computation algorithm is, in its numerical part, similar as in the former cases. While in the case of wormwheel machining with the special hob the tooth profile in the cross-section at the rim mid-width is symmetric (Fig. 4), for machining with the modular hob it is asymmetric Fig. 12. The machining errors (differences between profiles) are of the same order of magnitude as hob profile errors, so for modular hobs of enhanced accuracy (classes AA or AAA) they will be small (of the order of micrometres). A similar effect on the wormwheel tooth profile will be exhibited by the hob positioning error. A characteristic modular hob parameter, which is taken for 
the calculation of hob thread lead angle, is the analytical pitch diameter.

In general, this diameter is calculated allowing for blade backing-off, and is assumed at the blade mid-length (it considers the hob wear allowance). So, this must be taken into account when positioning the hob.

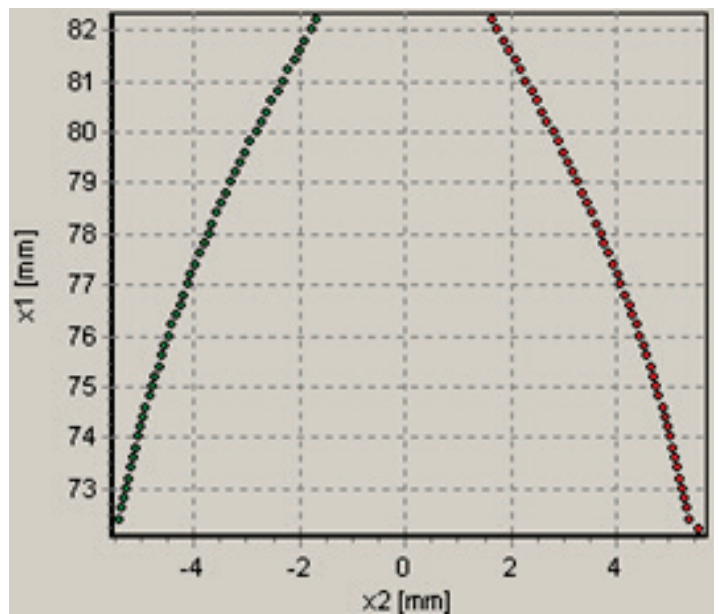

Figure 12 The wormwheel tooth profile in the cutting plane; module, 5; multiplicity, 1; pitch diameter, 45.277; number of wormwheel teeth, 30; distance of the worm and wormwheel axes, 126.36; modular hob pitch diameter, 94.5

\section{Conclusion}

The wormwheel surface was determined for the case of machining by the tangential and radial method, respectively. As tools, a (special) wormwheel machining hob and a modular hob were considered. Corrections allowing for the relative tool and wormwheel positioning errors were also introduced in the toothing cutting process. Each of the algorithms (programs) supports machining by either tangential or radial method (through the tool gradual cutting in), while in the second algorithm there is no need for solving the envelope condition.

In the first two programs, the surface of the worm is generated while taking into account its machining technology (depending on the type, geometric parameters and positioning of the tool), and only so defined worm helical surface is used for determining the surface of the wormwheel toothing. This means that, actually, it is not only the technological worm surface corresponding to the helical surface of the design worm mating a given wormwheel, but also the action surface of the special wormwheel machining hob that is determined.

If, however, for technological reasons, the action surface of the special hob (in the zone where the machined wormwheel is finishing shaped) is different from the assumed one, then the third program for determining the tooth surface of the wormwheel generated with the modular hob will support such tools as well. This program assumes that the axial profile of the tool's action surface is preset for the tool. Considering the fact that, as a result of the measurement (on a special measuring machine) or calculation of the cutting edge profile of a (modular or special wormwheel) hob, the axial profile of the hob action surface can be obtained (by moving the cutting edge points onto the hob axial plane by helical motion), it can be stated that, besides modular hobs, this program supports also such cases, and for either the radial or tangential method. The action surface of the modular hob, which was determined while considering its technology, was taken into account.

The errors of relative tool and machined wormwheel positioning are important in the wormwheel machining process.

Determining the wormwheel tooth surface for machining by the radial method enables the determination of the wormwheel distortion (truncation) resulting from the specificity of the method. Tooth surface truncation occurs (not always) at the tooth tip and is significant at large hob thread lead angles. Determining the wormwheel tooth profile as the tool cuts in, and comparing thus obtained profiles with one another in different crosssections on the wormwheel rim width may possibly allow the observation of this phenomenon.

The reduction of the number of wormwheel teeth has a very substantial effect on the tooth tip relief. The developed program enables this phenomenon to be eliminated at the worm gear design stage (the conditions for the elimination of this phenomenon, given in the literature, are approximate in character). The second (and the third) algorithm enables the determination of the transition curve and possible undercutting of the wormwheel tooth root.

The profile of the wormwheel machined with a modular hob in the cross-section at the wormwheel rim mid-width is asymmetric, while when being machined with a special hob, it is symmetric.

The accuracy and time of computation depend on the number of tool profile points under consideration and the number of cross-sections on the wormwheel rim width. The developed programs are analytical and numerical in character, and can be used in the process of the design, identification and analysis of the worm gear.

\section{References}

[1] Crosher, W. P. Design and Application of the Worm Gear. ASME Press, Michigan University, 2002. https://doi.org/10.1115/1.801780

[2] Siebert, H. Wom Gears - Higher Energy Efficiency and Less Strain on Resources. // Gear Technology. 5(2011), pp. 26-28.

[3] Products \& Services. Enclosed \& Open Gearing. http://www.renold.com.

[4] Dudas, I. The Theory and Practice of Worm Gear Drives. Penton Press, London, 2000.

[5] Litvin, F. L.; Fuentes, A. Gear Geometry and Applied Theory. Cambridge University Press, 2004. https://doi.org/10.1017/CBO9780511547126

[6] Bodzas, S.; Dudas, I. Designing of smoother hob. // Hungarian Journal of Industrial Chemistry, Veszprem, Vol 38(2), (2010), pp. 89-94.

[7] Nieszporek, T. Generating of worm gears of an arbitrary profile. Proceedings of th $11^{\text {th }}$ ASME International Power Transmission and Gearing Conference (PTG).// IDETC 2011-48297, August 28-31, 2011, Washington, USA, p. 5362. https://doi.org/10.1115/detc2011-48297

[8] Octrue, M. Relationship Between Wear and Pitting Phrnomena in Worm Gears. // Gear Technology. 5-6(1998), pp. 30-36.

[9] Stahl, K.; Hohl, B.-R.; Hermes, J.; Monz, A. Pitting Resistance of Worm Gears: Advanced Model for Contact Pattern of Any Size, Position, Flank Type. // Gear Technology. 10(2012), pp. 44-49. 
[10] Opalić, M.; Žeželj, D.; Vučković, K. A new method for description of the pitting process on wormwheels propagation. // Wear. 332-333, (2015), pp 1145-1150. https://doi.org/10.1016/j.wear.2015.01.053

[11] Litvin, F. L. Development of Gear Technology and Theory of Gearing. NASA RP-1406, 1998.

[12] Faster Worm Gear Production at Cleveland Gear. http://www.gleason.com.

[13] Fette. Gear Cutting Tools. Hobbing Gear Milling. Germany, $\quad$ No $1624 \quad(0405 \quad 1 \quad$ dtp/gk $)$, http://www.megatools.ru/catalog/lmt-fette/fettezubonareznoy-instrument.pdf.

[14] Dudas, I. Production of helicoids surfaces in intelligent systems. // Annals of MTeM for 2001 \& Proceedings of the $5^{\text {th }}$ International MTeM Symposium, Technical University of Cluj-Napoca, Romania, 2001, pp. 177-182.

[15] Hohn, B-R.; Steingrover, K.; Lotz, M. Determination and Optimization of the Contact Pattern of Worm Gears. // Gear Technology. 3-4(2003), pp. 12-17.

[16] Litvin, F. L.; Hasiao, C. L. Computerized simulation of meshing and contact of enveloping gear tooth surfaces. // Computer Methods in Applied Mechanical and Engineering, Holland. 102, (1993), pp. 337-366. https://doi.org/10.1016/0045-7825(93)90054-2

[17] Nieszporek, T. The basic principles of worm gear analysis. // Archiwum Technologii Budowy Maszyn i Automatyzacji KBM PAN Oddział w Poznaniu, vol. 18, nr 2, Poznań (1998), pp. 143-150.

[18] Litvin, F. L.; Kin, V. Computerized Simulation of Meshing and Bearing Contact for Single Enveloping Worm Gear Drives. // Journal of Mechanical Design. 114, 6(1992), pp. 312-317. https://doi.org/10.1115/1.2916948

[19] Markowski, T., Sobolak, M.; Numerical method of analysis of geometry of tool and workpiece mating area. $/ / 3^{\text {rd }}$ International Scientific Collquium CASE TECHNIQUES, Bielfeld, 1995, pp. 481-489.

[20] Litvin, F. L.; Gonzalez-Perez, I.; Yukishima, K.; Fuentes, A.; Hayasaka, K. Design, simulation of meshing, and contact stresses for an improved worm gear drive. // Mechanism and Machine Theory. 42, 8(2007), pp. 940-959. https://doi.org/10.1016/j.mechmachtheory.2006.08.005

[21] Vilmos, V. S. Influence of tooth errors and shaft misalignments on loaded tooth contact in cylindrical worm gears. // Mechanism and Machine Theory. 41, 6(2006), pp. 707-724. https://doi.org/10.1016/j.mechmachtheory.2005.09.004

[22] Stadtfeld, H. J. Worm Gears. // Gear Technology, 10(2013), pp. 51-52.

[23] Litvin, F. L. Theory of Gearing NASA Reference Publication 1212, Technical Report 88 C-035, 1989.

[24] Litvin, F. L. Gear geometry and applied theory. Prentice Hall, Englewood, New Jersey, 1994.

[25] Nieszporek, T.; Boral, P. The design and technology of cone worm. // The $3^{\text {td }}$ International Conference Mechanics, Rzeszów, 2002, pp. 259-264.

[26] Litvin, F. L.; Nava, A.; Fan, Q.; Fuentes, A.: New geometry of worm face gear drive with conical and cylindrical worms: Generation, simulation of meshing, and stress analysis. University of Illinois. Chicago, 2002.

\section{Authors' addresses}

Prof. Tadeusz Nieszporek, Dr hab. eng. Czestochowa University of Technology Institute of Mechanical Technologies Al. Armii Krajowej 21,

42-201 Czestochowa, Poland

E-mail: tadek@itm.pcz.pl

Rafal Golębski, Dr eng.

Czestochowa University of Technology

Institute of Mechanical Technologies

Al. Armii Krajowej 21,

42-201 Czestochowa, Poland

E-mail: rafal@itm.pcz.pl

\section{Lubomir Šooš, Prof. PhD. Ing.}

Slovak University of Technology in Bratislava

Mechanical Engineering Faculty

Namiestie Slobody 17

81231 Bratislava, Slovak Republic

E-mail: lubomir.soos@stuba.sk 